\title{
Effect of heated humidified ventilation on intraoperative core temperature and prognosis in normothermic thoraco-abdominal aortic aneurysm repair
}

\author{
Rui Zhao", Jiawei Qiu", Jinlin Wu, Wenxiang Jiang, Enzehua Xie, Wei Gao, Cuntao Yu, Juntao Qiu \\ Department of Cardiovascular Surgery, Fuwai Hospital, State Key Laboratory of Cardiovascular Disease, National Center for Cardiovascular \\ Diseases, Chinese Academy of Medical Sciences and Peking Union Medical College, Beijing 100037, China \\ Contributions: (I) Conception and design: C Yu, J Qiu; (II) Administrative support: C Yu; (III) Provision of study materials or patients: J Qiu; (IV) \\ Collection and assembly of data: R Zhao; (V) Data analysis and interpretation: R Zhao; (VI) Manuscript writing: All authors; (VII) Final approval of \\ manuscript: All authors. \\ \#These authors contributed equally to this work. \\ Correspondence to: Cuntao Yu, MD; Juntao Qiu, MD. Department of Cardiovascular Surgery, Fuwai Hospital, State Key Laboratory of Cardiovascular \\ Disease, National Center for Cardiovascular Diseases, Chinese Academy of Medical Sciences and Peking Union Medical College, 167 Beilishi Rd, \\ Beijing 100037, China. Email: cuntaoyu@126.com; 525572749@qq.com.
}

\begin{abstract}
Background: To evaluate whether the heated humidified ventilation can effectively maintain core temperature and improve prognosis in normothermic thoraco-abdominal aortic aneurysm repair surgery.

Methods: Patients who were scheduled for normothermic thoraco-abdominal aortic aneurysm repair surgery were randomized into the group using heated humidified ventilation combined with water blanket and the group using water blanket only. During the operation, the core temperature will be measured every 30 minutes. We analyzed intraoperative core-temperature, coagulation function and in-hospital mortality.

Results: HHV\&WB group showed lesser decrease in core temperature than WB groups in the first two hours, while WB group had a higher body temperature at the third to fifth hour (2-hour: $35.45 \pm 0.47 v$ s. $35.24 \pm 0.59^{\circ} \mathrm{C}, \mathrm{P}=0.284$; 5-hour: $35.38 \pm 0.70$ vs. $\left.35.51 \pm 0.88^{\circ} \mathrm{C}, \mathrm{P}=0.664\right)$. There was less blood loss, dosage of coagulation drugs and in-hospital mortality $(13.33 \%$ vs. $20.00 \%, \mathrm{P}=1)$ in the HHV\&WB group.

Conclusions: Heated humidified ventilation can improve the prognosis of normothermic thoracoabdominal aortic aneurysm repair surgery to some extent, but it can only maintain the core temperature during the first 2 hours.
\end{abstract}

Keywords: Aortic dissection; aortic aneurysm; hypothermia; humidity

Submitted Oct 24, 2019. Accepted for publication Dec 20, 2020.

doi: $10.21037 /$ jtd.2020.01.61

View this article at: http://dx.doi.org/10.21037/jtd.2020.01.61

\section{Introduction}

Thoraco-abdominal aortic aneurysm repair surgery is a challenging surgical procedure with long duration, wide incision exposure and multiple organs involved. In addition, during descending aorta replacement, deep hypothermic circulatory arrest (DHCA) is also required. This approach is associated with an incidence of spinal cord injury (SCI) of up to $13.9 \%$ and postoperative renal failure rates as high as $8 \%$ (1). Therefore, our center chose another normothermic surgery method, and found that it reduced early operative death and composited complications recently (2). This method does not reduce the incision length and the operation time is still long, allowing a hypothermic state to occur easily. Intraoperative hypothermia leads to many complications such as surgical wound infection and coagulation disorders $(3,4)$. In prevention of hypothermia and complications, many kinds of methods are used, such as forced air warmer, water blanket and heated humidified 
ventilation. Water blanket is considered to be one of the most effective methods of intraoperative heat preservation (5). Although we have applied water blanket during normothermic thoraco-abdominal aortic aneurysm repair surgery, the occurrence of intraoperative hypothermia cannot be avoided. We conducted a prospective analysis of patients undergoing normothermic thoraco-abdominal aortic aneurysm repair surgery with heated humidified ventilation. Intraoperative body temperature and early results were compared with those of patents who used heated humidified ventilation combined with water blanket and water blanket only, to evaluate whether the heated humidified ventilation can effectively maintain core temperature and improve prognosis.

\section{Methods}

\section{Patient selection}

Prospective, single-blind, randomized study was done with 40 patients, undergoing elective normothermic thoracoabdominal aortic aneurysm repair surgery from June 2018 to July 2019. We excluded the patients with preoperative temperature above $38{ }^{\circ} \mathrm{C}$, infectious aortic disease. Before starting this study, according to a computer-generated list of random numbers, patients were allocated randomly to one of the two groups. The two groups were: one (HHV\&WB, $\mathrm{n}=20$ ) used heated humidified ventilation (Respiratory Humidifier, Fisher \& Paykel Healthcare Ltd., New Zealand) combined with water blanket and the other $(\mathrm{WB}, \mathrm{n}=20)$ used water blanket only. We got informed consent from each patient preoperatively. We obtained ethical approval from the Institutional Review Board of Fuwai Hospital, Peking Union Medical College and Chinese Academy of Medical Sciences, China for this randomized controlled trail. The study was registered at Chinese Clinical Trail Registry (No. ChiCTR1900026573, available at: http:// www.chictr.org.cn).

\section{Body temperature monitoring}

We tried to maintain operating room temperature between 20 and $22{ }^{\circ} \mathrm{C}$, and room temperature was measured by electric thermometer placed onto the side wall of the operating room. Before the patient is anesthetized, water blankets were placed under the patient and heated humidified ventilation were connected to the anesthesia and respirator equipment. After patients lost self-respiration, a thermometer is inserted into the patient's rectum to record the core temperature and let the water blanket and heated humidified ventilation on. Total fresh gas flow was maintained at $3 \mathrm{~L} / \mathrm{min}$ throughout the operation. Heated humidified ventilation and water blanket were both set at $37{ }^{\circ} \mathrm{C}$. Core temperature was measured automatically every 5 minutes by anesthesia machine until the end of the surgery. We only analyzed the body temperature every half hour because of the long operation time. At the beginning of operation, no other warming devices were used. For severe hypothermia (less than $34^{\circ} \mathrm{C}$ ) during the operation, we planned to apply active warming methods such as forced air warmer for elevating temperature directly, so these cases were excluded.

\section{Surgical procedures}

As we published earlier (2), TAAA repair with normothermic iliac perfusion: the proximal thoracic aorta was isolated with the cross-clamp applied distal to the left subclavian artery. The proximal end of the 4-branched aortic graft was anastomosed to the proximal thoracic aorta distal to the end of the left subclavian artery; the distal end of the graft and the other 2 branches were occluded separately, after which the proximal thoracic aorta was unclamped. The cross-clamp was then moved down for proximal clamping of the abdominal aorta. The descending aorta were sutured to form an arterial tube (known as remodeling), which was then anastomosed with the 10-mm branch of the 4-branched vessel for restoration of blood flow to the spinal cord. After abdominal aortic cross-clamp release, a part of the abdominal aortic wall was shaped into a patch containing the origins of 3 arteries (the superior mesenteric artery, the coeliac axis and the right renal artery). The distal end of the 4-branched graft was anastomosed to the patch, followed by reperfusion of the above arterial vessels. An $8-\mathrm{mm}$ branch was anastomosed to the opening of the left renal artery to restore blood supply. Finally, the remaining 2 branches were separately anastomosed to the bilateral common iliac arteries.

When intraoperative aortic lesions were found to be inconsistent with preoperative imaging results, the surgical approach may be changed to thoracic aortic replacement or abdominal aortic replacement. These cases were excluded due to changes in the scope and timing of surgery. When the proximal anastomosis cannot be clamped during the operation and there is an uncontrollable tendency of massive bleeding, DHCA should be performed as soon as possible. 
Table 1 Patient preoperative information

\begin{tabular}{|c|c|c|c|}
\hline Variable & Heated Humidifiers \& Water Blanket, $n=15$ & Water Blanket, $n=15$ & $P$ value \\
\hline Height (cm) & $176.93 \pm 8.84$ & $176.33 \pm 11.69$ & 0.875 \\
\hline Weight (kg) & $79.07 \pm 13.39$ & $75.27 \pm 13.15$ & 0.439 \\
\hline Hypertension & $8(53.33)$ & $9(60.0)$ & 1 \\
\hline Diabetes mellitus & $1(6.67)$ & $1(6.67)$ & 1 \\
\hline Chronic renal failure & $0(0)$ & $0(0)$ & 1 \\
\hline COPD & $0(0)$ & $0(0)$ & 1 \\
\hline EF (\%) & $61.53 \pm 9.44$ & $61.99 \pm 4.18$ & 0.87 \\
\hline WBC $\left(10^{9} / \mathrm{L}\right)$ & $6.88 \pm 1.81$ & $6.93 \pm 2.83$ & 0.95 \\
\hline $\mathrm{Hb}(\mathrm{g} / \mathrm{L})$ & $138.33 \pm 22.46$ & $129.73 \pm 25.43$ & 0.34 \\
\hline Platelet $\left(10^{9} / \mathrm{L}\right)$ & $193.46 \pm 66.66$ & $183 \pm 50.33$ & 0.63 \\
\hline PT (s) & $14.27 \pm 2.51$ & $14.51 \pm 2.23$ & 0.78 \\
\hline
\end{tabular}

BMI, body mass index; COPD, chronic obstructive pulmonary disease; EF, ejection fraction; WBC, white blood cell count; Hb, hemoglobin; $\mathrm{PT}$, prothrombin time; INR, international normalized ratio; RR, respiratory rate.

In another situation, DHCA is required if the hypoxemia resulting from the use of one-side lung ventilation couldn't alleviated. These cases were also excluded because DHCA affected the operative body temperature.

\section{Outcome measures}

The primary outcome was the intraoperative temperature measured very half hour until 6 hours. We also measured the temperature at the end of the surgery and at postoperative recovery room immediately. In addition, intraoperative blood loss, activated clotting time of whole blood (ACT), amount of blood products, the dosage of coagulation drugs, and other indicators were compared. Secondary outcome was the in-hospital-mortality and complication rate.

\section{Statistical analysis}

Statistical analysis was performed with the use of $\mathrm{R}$ software (https://www.r-project.org). A 2-tailed P value $<0.05$ indicated statistical significance. Continuous variables were expressed as the mean with standard deviation or median with an interquartile range (IQR). Independent $t$-tests were performed for normally distributed variables; otherwise, the Mann-Whitney U-tests were done. Categorical variables were presented as frequencies with percentages and analysed by the Fisher's exact test. All preoperative variables shown in Table 1. 


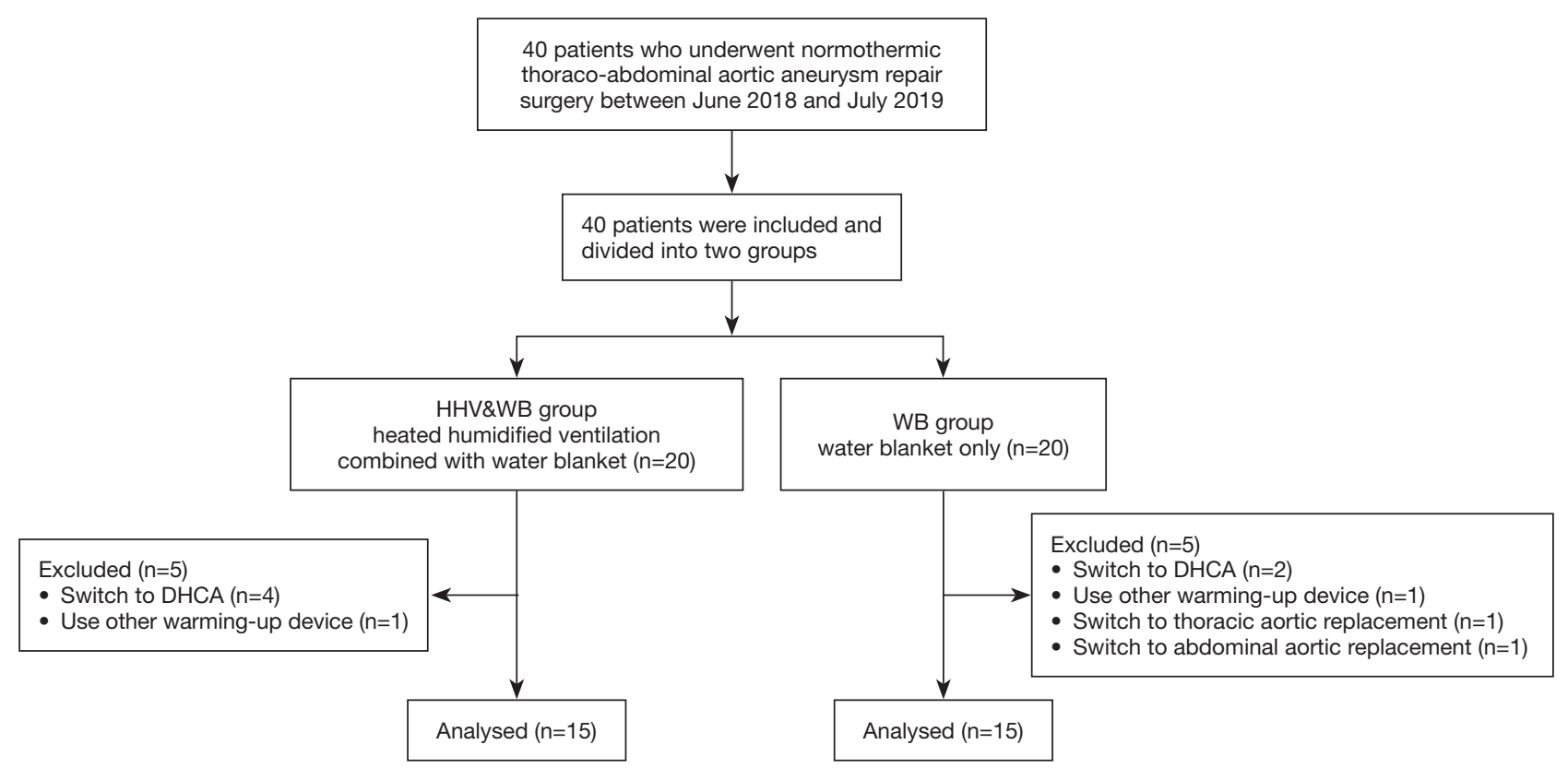

Figure 1 Patient enrolment flow diagram. This illustrates the flow of all the patients screened (including those who were excluded).

\section{Results}

\section{Baseline characteristics}

The patient enrollment flow diagram is shown in Figure 1. In total, 40 patients who underwent normothermic thoracoabdominal aortic aneurysm repair surgery between June 2018 and July 2019, were divided into two groups equally. Five patients were excluded in each group because of switch to other ways of surgery (including DHCA) or forced to use other warming-up device. Consequently, 30 patients remained after exclusions. The two groups were comparable regarding age, sex, body mass index (BMI), patient history, preoperative laboratory tests and preoperative temperature (Table 1).

\section{Intraoperative body temperature}

Core temperature decreased during first 60-minute, noticeably after 1 hour. No statistical differences were found among two groups on core temperature at any time point in term of the duration of surgery and recovery $(\mathrm{P}>0.05$, Table 2). However, we could find from the temperature curve that HHV\&WB group showed lesser decrease in core temperature than WB groups in the first 2 hours, while WB group had a higher body temperature at the third to fifth hour (Figure 2). The HHV group, although smaller in temperature range, was not statistically significant $\left(1.63 \pm 0.65\right.$ vs. $\left.1.67 \pm 0.45^{\circ} \mathrm{C}, \mathrm{P}=0.821\right)$.

\section{Intraoperative coagulation}

Duration of the procedure, intraoperative blood loss, activated clotting time of whole blood (ACT), amount of blood products, the dosage of coagulation drugs was compared between two groups (Table 3). There was no statistical difference in operation time between the two groups $(10.19 \pm 2.71$ vs. $9.89 \pm 3.26 \mathrm{~h}, \mathrm{P}=0.788)$. We found that ACT was significantly shortened in HHV\&WB group $(522.27 \pm 175.17$ vs. $675.79 \pm 197.93$ s, $\mathrm{P}<0.05)$. Although there was less blood loss (intraoperative determination of hemoglobin) and fewer dosage of coagulation drugs such as tranexamic acid (TXA), coagulation factor VIIa, prothrombin complex in the HHV\&WB group, there was no statistical difference. In the amount of blood products, except for red blood cells, the amount of platelet and plasma was lower than that of WB group. \{RBC input: $5.87 \pm 9.61$ vs. 4.89 $\pm 6.13, \mathrm{P}=0.75$; Plasma input: $400[0-800]$ vs. $500[0-$ 900], $\mathrm{P}=0.53$; PLT input: $1.93 \pm 0.88$ vs. $2.43 \pm 0.65, \mathrm{P}=0.098\}$.

\section{Postoperative outcomes}

The main adverse events are recorded in Table 4. Although 
no statistical difference in all postoperative events between the two groups was found, HHV\&WB group showed better results in most events except paralysis. HHV\&WB was also slightly shorter in terms of respirator use time and ICU

Table 2 Intraoperative temperature

\begin{tabular}{lccc}
\hline $\begin{array}{l}\text { Operation } \\
\text { time }\end{array}$ & $\begin{array}{c}\text { Heated Humidifiers } \\
\text { \& Water Blanket }\left({ }^{\circ} \mathrm{C}\right)\end{array}$ & $\begin{array}{c}\text { Water } \\
\text { Blanket }\left({ }^{\circ} \mathrm{C}\right)\end{array}$ & P value \\
\hline $0 \mathrm{~h}$ & $36.29 \pm 0.59$ & $36.36 \pm 0.48$ & 0.736 \\
$0.5 \mathrm{~h}$ & $36.06 \pm 0.56$ & $36.05 \pm 0.53$ & 0.947 \\
$1 \mathrm{~h}$ & $35.75 \pm 0.52$ & $35.69 \pm 0.61$ & 0.773 \\
$1.5 \mathrm{~h}$ & $35.55 \pm 0.67$ & $35.4 \pm 0.65$ & 0.548 \\
$2 \mathrm{~h}$ & $35.45 \pm 0.47$ & $35.24 \pm 0.59$ & 0.284 \\
$2.5 \mathrm{~h}$ & $35.32 \pm 0.45$ & $35.29 \pm 0.56$ & 0.887 \\
$3 \mathrm{~h}$ & $35.37 \pm 0.46$ & $35.41 \pm 0.70$ & 0.855 \\
$3.5 \mathrm{~h}$ & $35.24 \pm 0.56$ & $35.47 \pm 0.82$ & 0.385 \\
$4 \mathrm{~h}$ & $35.25 \pm 0.53$ & $35.48 \pm 0.78$ & 0.360 \\
$4.5 \mathrm{~h}$ & $35.33 \pm 0.58$ & $35.49 \pm 0.85$ & 0.569 \\
$5 \mathrm{~h}$ & $35.38 \pm 0.70$ & $35.51 \pm 0.88$ & 0.664 \\
$5.5 \mathrm{~h}$ & $35.54 \pm 0.69$ & $35.48 \pm 0.78$ & 0.826 \\
$6 \mathrm{~h}$ & $35.56 \pm 0.77$ & $35.5 \pm 0.78$ & 0.833 \\
End & $35.84 \pm 0.89$ & $35.79 \pm 0.7$ & 0.856 \\
$\mathrm{Tr}$ & $1.63 \pm 0.65$ & $1.67 \pm 0.45$ & 0.821 \\
$\mathrm{~T}, \mathrm{rm}$ & $36.6 \pm 0.92$ & $36.41 \pm 1.16$ & 0.617 \\
\hline
\end{tabular}

$\mathrm{Tr}$, temperature range; $\mathrm{T}, \mathrm{rm}$, temperature in recovery room. (intensive care unit) stay time \{respirator use time: 23 [13-67] vs. 37 [12-85] h, $\mathrm{P}=0.77$; ICU stay time: $154.03 \pm 132.50$ vs. $213.83 \pm 291.15 \mathrm{~h}, \mathrm{P}=0.82\}$. Most notably, the incidence of postoperative pneumonia in the $\mathrm{WB}$ group was twice than HHV\&WB group (26.67\% vs. $53.33 \%, \mathrm{P}=0.264)$, while wound infection was three times (6.67\% vs. 20.00\%, $\mathrm{P}=0.598)$.

\section{Discussion}

Thoraco-abdominal aortic aneurysm repair surgery is considered to be the largest type of surgery with a high incidence of postoperative mortality and complications. Many researchers have tried various methods to reduce the risk of such surgery (6-8). Compared to our previous studies (2), we included a larger group of older people, more women, and a larger percentage of patients who had had previous aortic surgery, which were factors contributing to the poor outcome. However, in our previous large sample size studies, the advantages of normothermic surgery were clearly demonstrated. DHCA can be avoided by normothermic surgery, which is considered to be able to reduce the risk (9). However, during the long operation, although we used water blanket, we still could not reduce the incidence of hypothermia, especially within the first two hours of surgery. This may lead to postoperative complications. Core temperature shows a three-phase temperature pattern: first, during one hour after the induction, it falls rapidly from 0.5 to $1{ }^{\circ} \mathrm{C}$. Second, this is followed by slow, linear decrease. Eventually, it finally plateaus after 2 to 4 hours of anesthesia (10). There is a

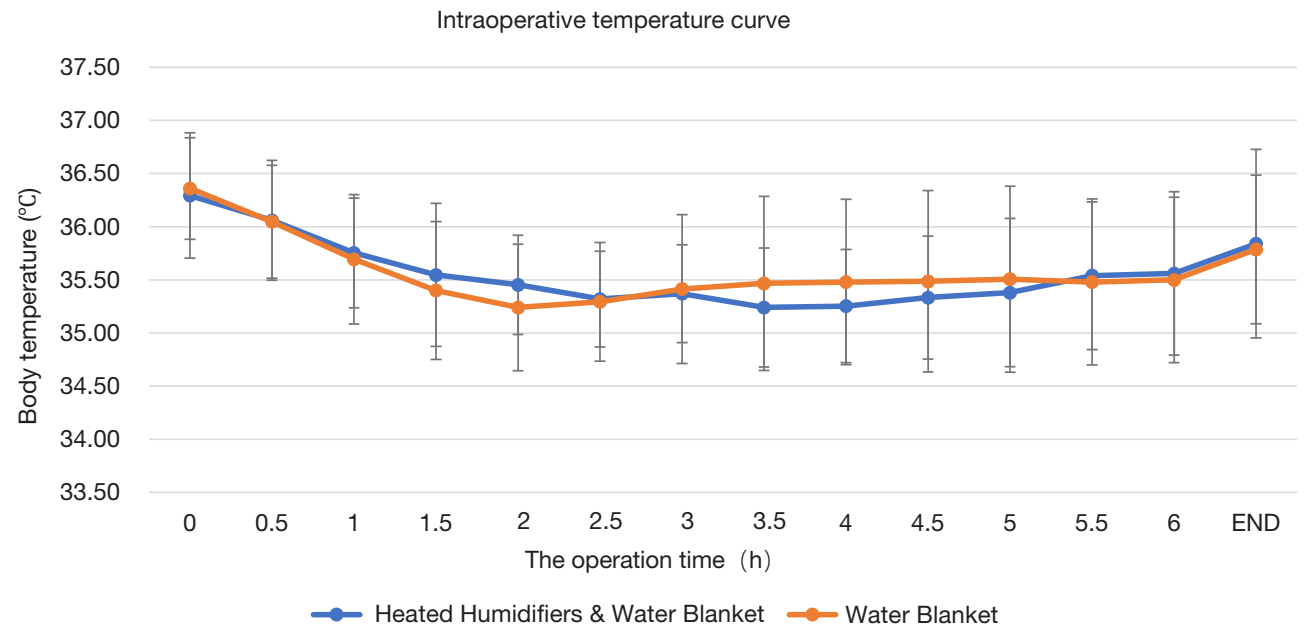

Figure 2 Intraoperative temperature curve, measured every half hour $\left({ }^{\circ} \mathrm{C}\right)$. 
Table 3 Intraoperative coagulation

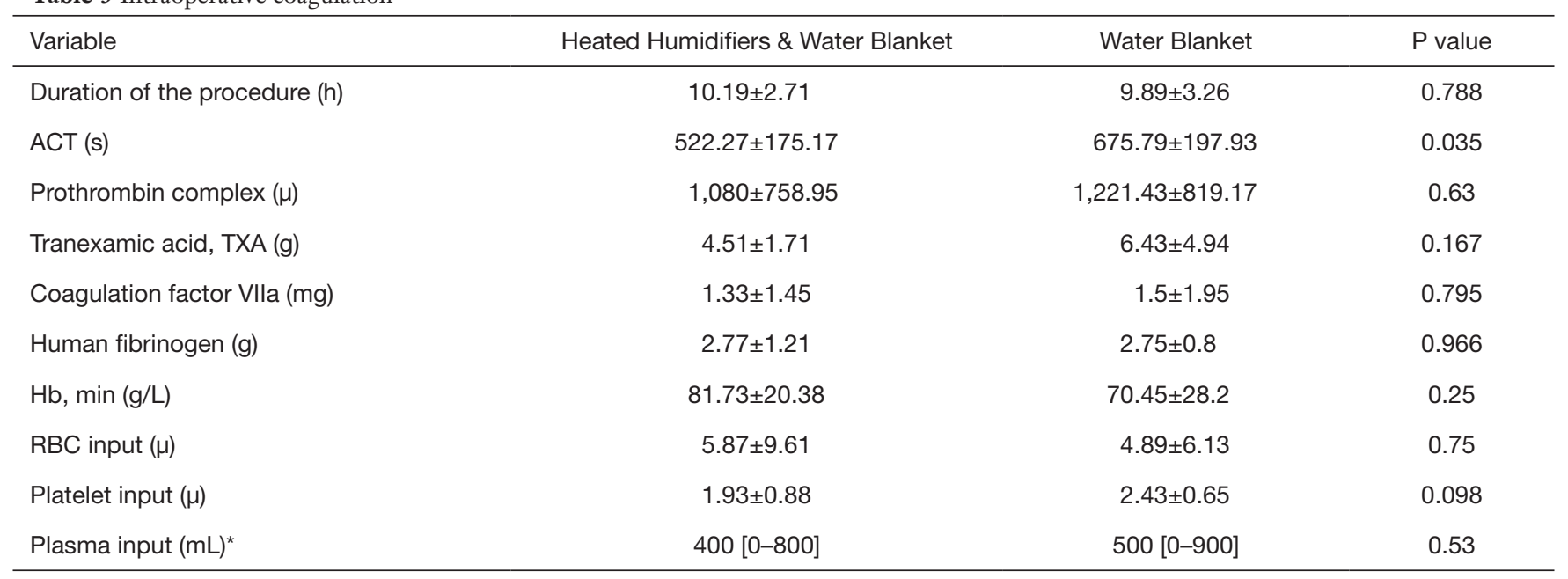

*, data were presented by IQR. ACT, activated clotting time; Hb, min: the minimum hemoglobin; RBC, red blood cell.

Table 4 Postoperative outcomes

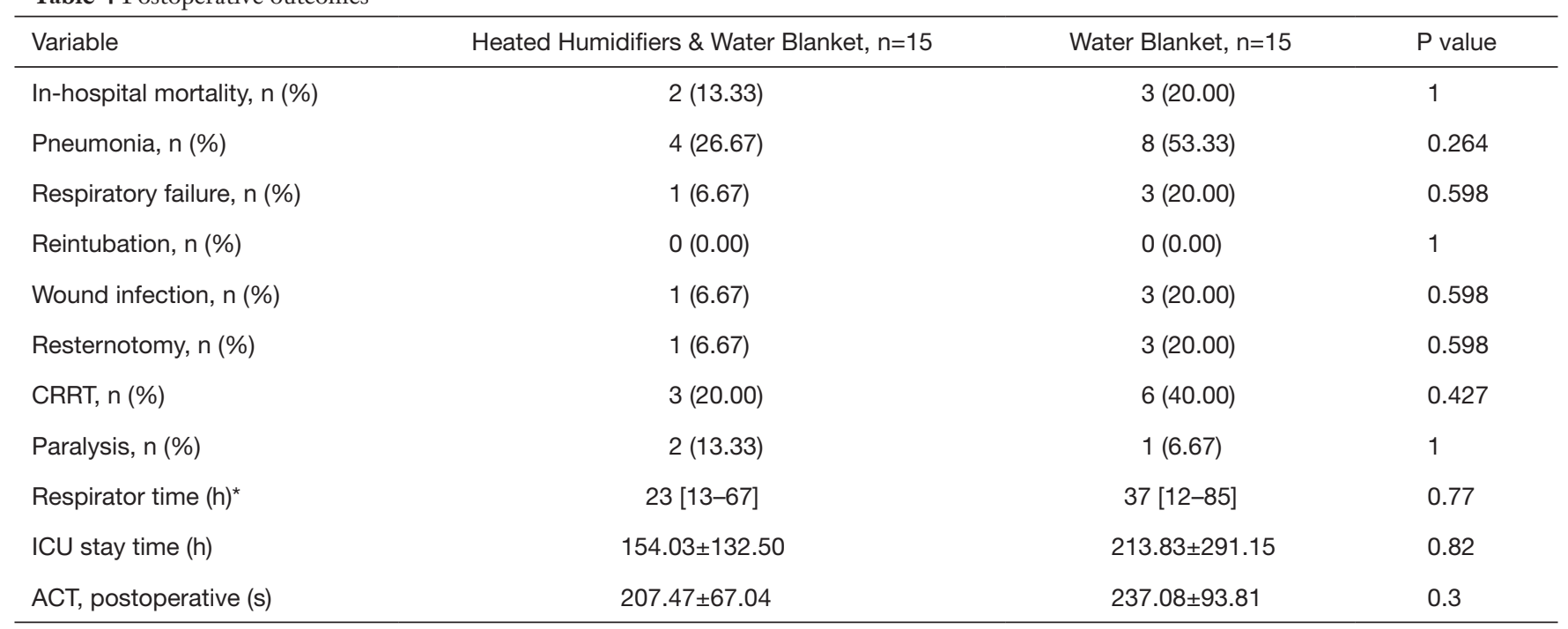

*, data were presented by IQR. CRRT, continuous renal replacement therapy; ICU, intensive care unit; ACT, activated clotting time.

study showed that heated humidified ventilation influences heat redistribution in early period of operation and can lessen the magnitude of the decrease in core body temperature. Therefore, it can be applied efficiently for other active warming devices in mild hypothermia (11). Therefore, we applied it combined with water blanket to find out whether the heated humidified ventilation can effectively maintain core temperature and improve prognosis. As we saw in the results, HHV did reduce hypothermia in the first two hours of surgery, but it failed in the third to fifth hours. When we look over many reviews, forced-air warmer is introduced more effective than circulating water blanket or heated humidifier in addition to some negative opinions about a heated humidifier in which core temperature became more hypothermic throughout the operation (5). That's probably because respiratory heat loss is smaller than radiative heat loss, heating and humidification cannot prevent the temperature drop (12). Combined with our results and published literature, we can find that HHV has a better heat preservation effect in the first 2 hours after surgery, but more than 2 hours may be counterproductive. 
From 34 to $35.9^{\circ} \mathrm{C}$, we call it mild hypothermia (13). Mild hypothermia significantly increases blood loss by approximately $16 \%(4-26 \%)$ and increases the relative risk for transfusion by approximately $22 \%(3-37 \%)$. Maintaining perioperative normothermia reduces blood loss and transfusion requirement by clinically important amounts (14). We performed multiple arterial blood gas analyses during the operation and recorded the lowest hemoglobin level. Since there was no significant difference in preoperative clinical test indicators between the two groups, we calculated intraoperative blood loss from the lowest intraoperative hemoglobin. We found that the lowest hemoglobin levels in the HHV\&WB group were higher than those in the WB group, so was the ACT. This partly confirms that $\mathrm{HHV}$ is effective.

Postoperative pulmonary infection is a common and relatively serious complication of thoraco-abdominal aortic aneurysm repair surgery (15). Because normothermic thoraco-abdominal aortic aneurysm repair surgery requires one-side lung ventilation to ensure the surgical field of vision, this is both a cause of lung infection and affects the effectiveness of HHV. HHV effectively maintains mucociliary clearance of patients during the general anesthesia, and it may reduce the risk of pulmonary infection to some extend (16). Hypothermia itself may delay healing and predispose patients to wound infections. Maintaining normothermia intraoperatively is likely to decrease the incidence of infectious complications in patients undergoing colorectal resection and to shorten their hospitalizations (3). In our study, both wound infection and ICU stay time were confirmed, although these results were not statistically significant. We think this is the limitation of our research, which We didn't include enough cases. First, as a challenging surgical procedure, normothermic thoracoabdominal aortic aneurysm repair surgery is only performed in about 20 cases per year in our center. Second, because of the emergency of most cases, we lost a lot of intraoperative data. Although the results obtained from these limited data have not been statistically verified, we can simply see that HHV\&WB improves prognosis to some extent. More data needs to be collected to verify these results.

\section{Acknowledgments}

Funding: This work was supported by grants from the Peking Union Medical College innovation fund project (2016E-CX10).

\section{Footnote}

Conflicts of Interest: The authors have no conflicts of interest to declare.

Ethical Statement: The authors are accountable for all aspects of the work in ensuring that questions related to the accuracy or integrity of any part of the work are appropriately investigated and resolved. We got informed consent from each patient preoperatively. We obtained ethical approval from the Institutional Review Board of Fuwai Hospital, Peking Union Medical College and Chinese Academy of Medical Sciences, China for this randomized controlled trail.

Open Access Statement: This is an Open Access article distributed in accordance with the Creative Commons Attribution-NonCommercial-NoDerivs 4.0 International License (CC BY-NC-ND 4.0), which permits the noncommercial replication and distribution of the article with the strict proviso that no changes or edits are made and the original work is properly cited (including links to both the formal publication through the relevant DOI and the license). See: https://creativecommons.org/licenses/by-nc-nd/4.0/.

\section{References}

1. Fehrenbacher JW, Siderys H, Terry C, et al. Early and late results of descending thoracic and thoracoabdominal aortic aneurysm open repair with deep hypothermia and circulatory arrest. J Thorac Cardiovasc Surg 2010;140:S154-60; discussion S185-90.

2. Zhang L, Yu C, Yang X, et al. Normothermic iliac perfusion improves early outcomes after thoracoabdominal aortic aneurysm repair. Eur J Cardiothorac Surg 2019;55:1054-60.

3. Kurz A, Sessler DI, Lenhardt R. Perioperative normothermia to reduce the incidence of surgicalwound infection and shorten hospitalization. Study of Wound Infection and Temperature Group. N Engl J Med 1996;334:1209-15.

4. Sessler DI. Complications and treatment of mild hypothermia. Anesthesiology 2001;95:531-43.

5. Hynson JM, Sessler DI. Intraoperative warming therapies: a comparison of three devices. J Clin Anesth 1992;4:194-9.

6. Coselli JS, LeMaire SA, Köksoy C, et al. Cerebrospinal fluid drainage reduces paraplegia after thoracoabdominal aortic aneurysm repair: results of a randomized clinical 
trial. J Vasc Surg 2002;35:631-9.

7. Chuter TA, Reilly LM. Endovascular treatment of thoracoabdominal aortic aneurysms. J Cardiovasc Surg (Torino) 2006;47:619-28.

8. Nakajima M, Aomi S, Nonoyama M, et al. Comparative study of hypothermic circulatory arrest and normothermic distal perfusion for thoracoabdominal aortic aneurysm repair. Kyobu Geka 2003;56:175-80, 180-2.

9. LeMaire SA, Price MD, Green SY, Zarda S, Coselli JS. Results of open thoracoabdominal aortic aneurysm repair. Ann Cardiothorac Surg 2012;1:286-92.

10. Sessler DI. Perioperative heat balance. Anesthesiology 2000;92:578-96.

11. Park HJ, Moon HS, Moon SH, et al. The effect of humidified heated breathing circuit on core body temperature in perioperative hypothermia during thyroid surgery. Int J Med Sci 2017;14:791-7.

Cite this article as: Zhao R, Qiu J, Wu J, Jiang W, Xie E, Gao W, Yu C, Qiu J. Effect of heated humidified ventilation on intraoperative core temperature and prognosis in normothermic thoraco-abdominal aortic aneurysm repair. J Thorac Dis 2020;12(3):276-283. doi: 10.21037/jtd.2020.01.61
12. Ouellette RG. Comparison of four intraoperative warming devices. AANA J 1993;61:394-6.

13. Kurz A. Thermal care in the perioperative period. Best Pract Res Clin Anaesthesiol 2008;22:39-62.

14. Rajagopalan S, Mascha E, Na J, et al. The effects of mild perioperative hypothermia on blood loss and transfusion requirement. Anesthesiology 2008;108:71-7.

15. Etz CD, Di Luozzo G, Bello R, et al. Pulmonary complications after descending thoracic and thoracoabdominal aortic aneurysm repair: predictors, prevention, and treatment. Ann Thorac Surg 2007;83:S870-6; discussion S890-2.

16. Seo H, Kim SH, Choi JH, et al. Effect of heated humidified ventilation on bronchial mucus transport velocity in general anaesthesia: a randomized trial. J Int Med Res 2014;42:1222-31. 